Section VII

Congress

Appendix: answers to multiple choice questions 


\section{Appendix: answers to multiple choice questions}

\section{VETERINARY}

\section{Thursday 2 April}

\section{GI FROM TOP TO BOTTOM}

Difficult to swallow? Dysphagia/oesophageal disease $1=D, 2=B, 3=A$ Approach to chronic vomiting and diarrhoea $1=B, 2=D, 3=C$ Introduction to $\mathrm{Gl}$ endoscopy 1=D, 2=C, 3=A

Interpreting $\mathrm{Gl}$ histopathology results from top to bottom 1=C, 2=B $3=\mathrm{A}$

Colorectal disease $1=\mathrm{B}, 2=\mathrm{C}, 3=\mathrm{C}$

The lumpy gut: a review of $\mathrm{Gl}$ neoplasia 1=D, 2=A, 3=A

Gl bugs: friend or foe? An update on bacterial gastrointestinal disease $1=B, 2=C, 3=A$

\section{COMMON CONSULTS}

My rabbit has a dirty bottom 1=A, 2=B, 3=D

My rabbit is off its food 1=C, 2=D, $3=C$

My rabbit has a head tilt $1=C, 2=D, 3=A$

My rabbit has a watery eye $1=C, 2=B, 3=D$

Does my bitch need a caesarean? $1=\mathrm{C}, 2=\mathrm{A}, 3=\mathrm{C}$

How am I going to perform the caesarean? $1=C, 2=B, 3=A$

My dog is itchy $1=B, 2=B, 3=C$

My cat is bald $1=A, 2=C, 3=B$

My dog is lame $1=\mathrm{A}, 2=\mathrm{A}, 3=\mathrm{C}$

My dog is wobbly $1=C, 2=D, 3=B$

My cat is sneezing $1=B, 2=A, 3=B$

My cat is pale $1=B, 2=D, 3=A$

My cat is straining $1=A, 2=B, 3=C$

My cat is urinating outside the litter box 1=B, 2=B, 3=A

\section{ORTHOPAEDICS FOR BEGINNERS}

Trauma examination and stabilisation $1=B, 2=C, 3=A$

Fracture diagnosis and assessment $1=D, 2=C, 3=B$

External skeletal fixation 1=A, 2=D, 3=B

Internal fixation $1=\mathrm{D}, 2=\mathrm{D}, 3=\mathrm{B}$

My first fracture $1=B, 2=C, 3=B$

Postoperative radiographic evaluation: should I go back? 1=B, 2=C $3=\mathrm{D}$

It SHOULD be healed by now. 1=D, 2=B, 3=B

\section{AVP: SURGERY}

Getting the most out of your laparoscopic kit: canine 1=C, 2=B, 3=C Getting the most out of your laparoscopic kit: feline 1=C, 2=C, 3=D Angular limb deformities 1=A, 2=D, 3=D

Getting the most out of surgical staplers 1=A, 2=B, 3=B

\section{AVP: ANAESTHESIA}

Getting the most out of preoperative analgesia 1=D, 2=C, 3=A Getting the most out of loco regional analgesia $1=D, 2=C, 3=A$ Building an effective anaesthesia and analgesia plan $1=\mathrm{D}, 2=\mathrm{C}, 3=\mathrm{A}$ Dealing with common anaesthetic problems $1=C, 2=B, 3=A$

\section{Friday 3 April}

\section{OPHTHALMOLOGY}

Canine conjunctivitis: causes and treatment $1=C, 2=C, 3=A$

Feline conjunctivitis: causes and treatment $1=B, 2=D, 3=B$

Ocular or systemic disease? 1=A, 2=A, 3=B

Which drops to drop: ocular drugs for your practice 1=A, 2=B, 3=A

Cataracts $1=D, 2=C, 3=D$

Keratoconjunctivitis sicca $1=\mathrm{D}, 2=\mathrm{A}, 3=\mathrm{D}$

Canine eyelid in health and disease $1=A, 2=D, 3=D$

Ocular emergencies $1=\mathrm{C}, 2=\mathrm{A}, 3=\mathrm{B}$

\section{INFECTIOUS DISEASES}

Alabama rot: where are we now? 1=B, 2=A, 3=C

A practical guide to zoonotic diseases: what do I need to tell clients? $1=\mathrm{C}, 2=\mathrm{B}, 3=\mathrm{D}$
Leptospirosis: an old dog with new tricks 1=B, 2=A, 3=C

Lungworm: what's new in management and prevention? $1=\mathrm{B}, 3=\mathrm{C}, 3=\mathrm{A}$ Urinary tract infection or subclinical bacteriuria: what's the difference and when to treat? $1=C, 2=A, 3=A$

Infectious respiratory disease: an update 1=C, 2=D, 3=B

Living with Leishmania 1=C, 2=A, 3=B

Tick borne diseases: which ones do I actually need to know about? $1=\mathrm{A}, 2=\mathrm{B}, 3=\mathrm{C}$

\section{CHALLENGES IN IMAGING}

When radiologists make mistakes $1=B, 2=A, 3=D$

Pitfalls in abdominal radiology $1=D, 2=B, 3=C$

It'll be alright at night: pitfalls in image interpretation in the trauma patient $1=\mathrm{C}, 2=\mathrm{B}, 3=\mathrm{B}$

Pitfalls in thoracic radiology $1=\mathrm{A}, 2=\mathrm{D}, 3=\mathrm{A}$

Pitfalls in abdominal ultrasonography: Part I 1=C, 2=A, 3=A

Pitfalls in abdominal ultrasonography: Part Il $1=A, 2=D, 3=B$

Thoracic imaging: cases where mistakes may be made $1=C, 2=A, 3=A$ Abdominal imaging; cases where mistakes may be made $1=A, 2=B$, $3=\mathrm{C}$

\section{WHAT'S YOUR DIAGNOSIS}

$\mathrm{PU} / \mathrm{PD} 1=\mathrm{C}, 2=\mathrm{C}, 3=\mathrm{C}$

The jaundiced $\operatorname{dog} 1=D, 2=D, 3=A$

The dog with epistaxis $1=C, 2=B, 3=C$

Unusual patterns of oestrus $1=B, 2=D, 3=B$

The rabbit with weight loss $1=\mathrm{D}, 2=\mathrm{D}, 3=\mathrm{A}$

Canine skin masses $1=D, 2=C, 3=B$

The tachypnoeic cat $1=A, 2=B, 3=C$

Feline abdominal mass $1=A, 2=C, 3=D$

\section{Saturday 4 April}

\section{DERMATOLOGY}

Consult room diagnostics in dermatology $1=A, 2=A, 3=A$

Ears: what do they really look like? $1=\mathrm{A}, 2=\mathrm{A}, 3=\mathrm{A}$

Otitis: what really causes it? $1=\mathrm{D}, 2=\mathrm{A}, 3=\mathrm{C}$

Chronic end stage otitis: treatment and prevention $1=A, 2=B, 3=D$

An approach to the itchy dog $1=D, 2=C, 3=A$

Understanding allergies $1=A, 2=B, 3=A$

Food allergies $1=\mathrm{A}, 2=\mathrm{B}, 3=\mathrm{B}$

Anti-pruritic drugs $20201=\mathrm{D}, 2=\mathrm{C}, 3=\mathrm{B}$

\section{EXOTICS}

Loco regional anaesthesia in exotic pets (mammals, reptiles and birds) $1=\mathrm{D}, 2=\mathrm{D}, 3=\mathrm{D}$

Updates on small mammal dermatology $1=B, 2=A, 3=A$

Managing rabbits and rodents: urinary disorders $1=D, 2=D, 3=D$

Anaesthesia and pain management in fish: reconsidering fish $n^{\prime}$ chips? $1=\mathrm{D}, 2=\mathrm{A}, 3=\mathrm{C}$

Reproductive medicine in reptiles: hormones to surgery $1=\mathrm{A}, 2=\mathrm{C}$, $3=\mathrm{C}$

Viruses, bacteria and fungi...oh my! Infectious diseases of exotic small mammals $1=D, 2=C, 3=D$

Blood cells and biochemistries: is bloodwork useful for managing cap tive psittacines? $1=A, 2=D, 3=B$

Updates in exotic animal oncology $1=D, 2=D, 3=D$

\section{ONCOLOGY}

MCTs with bad intentions? The good, the bad and the ugly $1=\mathrm{D}, 2=\mathrm{B}$ $3=\mathrm{D}$

Chemotherapy for MCTs $1=\mathrm{C}, 2=\mathrm{A}, 3=\mathrm{B}$

Difficult MCTs and dirty margins (With Sarah Mason) 1=B, 2=D, 3=B

Difficult MCTs and dirty margins (With Nick Bacon) $1=B, 2=D, 3=B$

Evaluating the canine lymphoma patient 1=B, 2=A, 3=A

Chemotherapy for lymphoma: more than $\mathrm{COP}, \mathrm{CHOP}$ and beyond $1=C, 2=D, 3=A$

Should you treat cats with lymphoma like dogs? $1=D, 2=B, 3=C$

Strange, but not beautiful: how to manage unusual lymphoma cases $1=B, 2=A, 3=C$ 


\section{AVP: DIAGNOSTIC IMAGING}

Head tilt or head turn: neurolocalization of the head and what difference does it make? $1=C, 2=A, 3=D$

What do you need to know about brain MRI? 1=D, 2=A, $3=B$

Leaky pipes or blocked drains: urinary contrast studies in $20201=A$, $2=\mathrm{D}, 3=\mathrm{B}$

How to image a suspected foreign body $1=C, 2=D, 3=C$

\section{Sunday 5 April}

\section{ENDOCRINE \& ADVANCED ENDOCRINE}

What's new in the monitoring of hyperadrenocorticism? $1=\mathrm{D}, 2=\mathrm{C}$, 3=B

Adrenal incidentaloma: when should I worry 1=A, 2=B, 3=C

What's new in the monitoring of canine diabetes mellitus? $1=A, 2=D$, $3=\mathrm{D}$

Emergency endocrine cases: glucose gone wrong. 1. Pragmatic approach to managing a DKA patient $1=A, 2=D, 3=D$

Emergency endocrine cases: glucose gone wrong. 2. Pragmatic approach to managing an insulinoma $1=C, 2=B, 3=A$

Feline acromegaly: what options should we be discussing with clients? 1=A, 2=C, $3=\mathrm{A}$

Endocrine diagnostics: staying out of the 'grey zone' 1 . Interpreting thyroid tests $1=A, 2=D, 3=B$

Endocrine diagnostics: staying out of the 'grey zone' 2. Interpreting adrenal tests $1=\mathrm{D}, 2=\mathrm{C}, 3=\mathrm{C}$

Weak/wobbly/weird: when endocrinology masquerades as neurology $1=B, 2=D, 3=A$

\section{SOFT TISSUE}

Presurgical imaging of the head $1=D, 2=B, 3=D$

Surgical management of nasal disease $1=D, 2=B, 3=D$

Surgical management of ear disease $1=B, 2=B, 3=A$

Finding cause of facial swelling $1=D, 2=C, 3=C$

Oral tumours: basic $1=C, 2=B, 3=A$

Oral tumours: advanced 1=B, 2=D, 3=B

Mapping lymph nodes: the whys and the wherefores $1=B, 2=D, 3=D$

\section{NURSING}

\section{Thursday 2 April}

\section{ADVANCED NURSING: ANALGESIA}

Exotic small mammal pain management $1=B, 2=D, 3=A$

Local and regional nerve blocks $1=B, 2=A, 3=D$

Feline: what's new in pain recognition and scoring? $1=D, 2=B, 3=D$

Canine: what's new in pain recognition and scoring? $1=B, 2=B, 3=B$

A review of medical cannabis $1=D, 2=A, 3=D$

New directions in pain management $1=A, 2=D, 3=B$

\section{FELINE}

How to nurse cats with lower urinary tract disease $1=C, 2=B, 3=D$

Hepatic lipidosis $1=B, 2=A, 3=D$

The insulin-resistant cat: acromegaly $1=B, 2=C, 3=A$

Feline blood transfusions $1=C, 2=B, 3=C$

Keeping the hospitalized cat happy $1=D, 2=A, 3=B$

Common toxicites $1=B, 2=C, 3=A$

\section{BOAS}

BOAS: what is it and how we can manage it? $1=B, 2=D, 3=A$

Emergency management of BOAS patients $1=C, 2=C, 3=B$

Ophthalmology considerations for brachycephalics $1=A, 2=D, 3=C$

Nutrition: are BOAS breeds different? 1=A, 2=D, $3=\mathrm{D}$

What the clinic nurse needs to know $1=C, 2=A, 3=D$

Anaesthesia of brachycephalics $1=C, 2=D, 3=A$

\section{Friday 3 April}

\section{ANAESTHESIA}

The highs and lows of $\mathrm{ETCO}_{2} 1=\mathrm{A}, 2=\mathrm{C}, 3=\mathrm{B}$

Pink or blue: why and when to use pulse oximetry $1=A, 2=D, 3=A$

Update on perioperative fluid therapy $1=\mathrm{D}, 2=\mathrm{C}, 3=\mathrm{C}$

My patient's hypotensive, what should I do? 1=A, 2=A, $3=A$

Intubation: dogs, cats and rabbits $1=C, 2=A, 3=D$

It doesn't end here: anaesthetic recovery $1=C, 2=D, 3=B$

Anaesthesia for the $C K D$ patient $1=A, 2=A, 3=A$

Anaesthesia for the cardiac patient 1=A, 2=A, 3=A

\section{CANINE MEDICINE}

Don't be an autoimmune autopilot! 1=A, 2=D, 3=A

Vomiting-control medication: when, how and why $1=A, 2=C, 3=D$

The top to bottom of endoscopy: a practical approach $1=B, 2=C, 3=D$

Low-stress bronchoscopy 1=C, 2=B, 3=D

All the maths: clinical calculations revisited and reworked $1=C, 2=C$ 3=D

Pet blood bank: overview and how practices can assist $1=C, 2=B, 3=D$ $4=\mathrm{D}$

Nursing the megaoesophagus patient $1=\mathrm{A}, 2=\mathrm{C}, 3=\mathrm{A}$

Overview of renal disease $1=B, 2=D, 3=A$

\section{NUTRITION}

Rabbit nutrition Part I: the good, the bad and the ugly $1=A, 2=C, 3=A$

Rabbit nutrition Part II: associated problems including anaesthetic considerations $1=\mathrm{D}, 2=\mathrm{C}, 3=\mathrm{B}$

Obesity in canines: prevention better than cure 1=D, 2=A, $3=B$

What's new with pre-procedural starving? $1=C, 2=A, 3=B$

Post-procedural nutritional requirement $1=A, 2=D, 3=D$

Obesity in felines $1=D, 2=C, 3=A$

Nutrition for cats with $\mathrm{Gl}$ issues $1=\mathrm{A}, 2=\mathrm{C}, 3=\mathrm{B}$

Geriatric cats: what can they eat? $1=\mathrm{D}, 2=\mathrm{B}, 3=\mathrm{A}$

\section{Saturday 4 April}

\section{NEUROLOGY}

Nursing the seizure patient $1=A, 2=B, 3=C$

Nursing the vestibular patient $1=C, 2=A, 3=D$

Bladder management in the neurological patient $1=A, 2=C, 3=D$

Nursing considerations for the spinal patient $1=C, 2=B, 3=D$

Nursing neurological examination and when to worry $1=C, 2=B, 3=D$

Nursing the neuro muscular patient $1=C, 2=D, 3=A$

What nurses need to know about inflammatory brain disease $1=C$ $2=\mathrm{D}, 3=\mathrm{B}$

Neurology trauma emergencies $1=B, 2=C, 3=D$

\section{CARDIOLOGY \& ADVANCED CARDIOLOGY}

Nursing the cardiac crisis $1=B, 2=B, 3=D$

Do you hear what I hear? Heart sounds for everyone $1=C, 2=A, 3=D$

How to read an ECG 1=A, 2=A, 3=C

Long-term monitoring of the cardiac patient $1=\mathrm{D}, 2=\mathrm{D}, 3=\mathrm{A}$

Emergency management of arrhythmias $1=D, 2=A, 3=B$

Mitral valve disease and hypertrophic cardiomyopathy $1=\mathrm{D}, 2=\mathrm{D}$ $3=$ True

A review of congenital heart conditions $1=D, 2=C, 3=A$

Pacemakers 1=B, 2=A, 3=D

\section{SURGICAL/THEATRE}

Why checklists are the RVN's best friend 1=A, 2=B, 3=C

In-practice practical approach to surgical rehabilitation $1=B, 2=A, 3=B$

Rehabilitation in the referral setting: when and why is this appropriate $1=\mathrm{A}, 2=\mathrm{D}, 3=\mathrm{C}$

Discharge planning and management at home $1=B, 2=B, 3=C$ 


\section{Appendix: answers to multiple choice questions}

Skin prep: is there a RIGHT way? $1=C, 2=A, 3=C$

Safety in surgery: human factors 1=A, 2=A, 3=A

Look after your kit and it will look after you 1=C, $2=A, 3 C$

Surgery into the beyond: how to mend a broken heart $1=A, 2=C, 3=A$

\section{Sunday 5 April}

ECC

Minimum database, one flashback is all it takes $1=B, 2=C, 3=D$

Major body systems assessments $1=C, 2=C, 3=C$

Pleural space disease: what are you doing there? $1=D, 2=D, 3=D$

Heat exchange: loss, gain and management demystified $1=C, 2=A$ $3=\mathrm{C}$

Coagulation tests: what does this all mean? $1=C, 2=B, 3=D$

Hypotension: cause, effect and management $1=A, 2=B$

\section{DISTRICT VETERINARY NURSING}

Advances in veterinary palliative care at home $1=C, 2=B, 3=C$

Clinical examinations at home: using eyes and ears to aid collaborative veterinary care $1=B, 2=A, 3=B$

Recognizing stressors at home: impact on the patients emotional and physical health and recovery $1=D, 2=C, 3=B$

\section{BEHAVIOUR, ETHICS \& WELFARE}

Practical considerations when treating pets of owners of no fixed abode: treatment priorities, implementation and compliance $1=C$ $2=\mathrm{A}, 3=\mathrm{B}$

Practical considerations when treating pets of owners of no fixed abode: the veterinary team as inclusion medicine allied health professionals $1=C, 2=B, 3=D$

What it means to be small and smart $1=B, 2=C, 3=C$

Punishment: should we, do we, why? $1=A, 2=C, 3=B$

I am not a human: please speak clearly $1=C, 2=C, 3=C$

\section{MANAGEMENT}

\section{Thursday 2 April}

\section{UNDERSTANDING EMPATHY}

Introducing the human-companion animal bond $\&$ understanding the pet owner $1=D, 2=A, 3=D$

Bond-centred end-of-life care: mindset, challenges and protocols $1=\mathrm{D}, 2=\mathrm{A}, 3=\mathrm{D}$

The client journey: supporting the client before and after the last appointment $1=D, 2=D, 3=D$

\section{VETLIFE}

Caring for carers: understanding emotional labour and supporting staff 1=A, 2=D, 3=D

Compassion fatigue: what is it and how can you help? $1=A, 2=D, 3=B$ Building and supporting compassionate teams: what helps? $1=C, 2=D$, $3=\mathrm{C}$

What to do when you don't know what to do: case studies for dealing with difficult situations $1=D, 2=B, 3=B$

\section{Friday 3 April}

\section{LEADERSHIP PROGRAMME}

People, planet, profit: sustainability and leading change $1=A, 2=B, 3=D$ What did you just say? The power to influence with communication strategy $1=\mathrm{D}, 2=\mathrm{A}, 3=\mathrm{D}$

The green ninja: an NHS case study in sustainability $1=C, 2=B, 3=D$

Waste not want not: a case study from veterinary practice $1=A, 2=D$, $3=\mathrm{A}$

Where do you think you're going? Part I \& Part II 1=D, 2=A, 3=A

\section{Saturday 4 April}

\section{MANAGEMENT: VMG}

Developing a learning culture: using feedback as a gift for developing and motivating your team $1=A, 2=D, 3=D$

We are going through changes: simple techniques to keep yourself and team engaged during times of change $1=A, 2=B, 3=C$

The employee journey: the part you play in ensuring your team has a positive workplace experience $1=C, 2=A, 3=D$

Turnover is vanity, profit is sanity: managing the bottom line $1=D, 2=D$, $3=\mathrm{B}$

Measuring and improving our quality of care $1=B, 2=C, 3=B$

User-focused services: understanding your clients needs, as well as your team's 1=D, 2=B, 3=A

\section{Sunday 5 April}

\section{MANAGEMENT}

Why carrot and stick doesn't work: motivation is an inside job 1=A, 2=B, 3=D

Ready, aim, fire: how to hit the target every time 1=D, 2=B, 3=D

Meaningful metrics that matter: how to pick the right ones $1=D, 2=B$ $3=\mathrm{C}$

Keeping the flame burning; creating a culture of excellence $1=A, 2=C$ $3=\mathrm{B}$

Failing to plan is planning to fail: getting the process right $1=C, 2=D$, $3=\mathrm{D}$

The generation game: managing different generations - everything you need to know but were afraid to ask $1=D, 2=D, 3=B$

Effective appraisals: a two-way process $1=D, 2=C, 3=D$

\section{OPEN TO ALL}

\section{Thursday 2 April}

\section{CARDIOLOGY: WHEN TO WORRY}

Dangerous arrhythmias: getting and interpreting the ECG in the heat of the moment 1=C, 2=D, 3=D

Bradyarrhythmias: when to worry 1=B, 2=B, 3=A

Tachyarrhythmias: when to worry 1=C, 2=D, 3=B

Arrhythmias in congestive heart failure $1=D, 2=B, 3=B$

Arrhythmias in cats: when to worry 1=C, 2=D, 3=B

Intermittent collapse: top tips whether fit or faint 1=C, 2=D, 3=D

Worse with treatment: don't make these mistakes $1=D, 2=B, 3=A$

\section{RCVS \& RCVS VN FUTURES}

Graduate Outcomes Consultation: where are we and what's happening next? $1=\mathrm{B}, 2=\mathrm{A}, 3=\mathrm{B}$

What is outcomes based CPD and what do I need to do? $1=A, 2=B, 3=C$ Mind matters: about Schwartz Rounds; experience a Schwartz Round $1=\mathrm{D}, 2=\mathrm{B}, 3=\mathrm{C}$

Nursing in the community: the potential of the community nurse role in One Health $1=B, 2=C, 3=D$

\section{REHABILITATION}

Chronic pain: a heterogenic disease - predictors, construct, challenges of measurement $1=A, 2=D, 3=C$

Chronic pain: a practical approach to multimodal management - diagnosis and surgical options for chronic joint pain $1=A, 2=B, 3=C$

Chronic pain: a practical approach to multimodal management rehabilitation with non medical therapies and acupuncture $1=\mathrm{D}, 2=\mathrm{B}$ $3=\mathrm{C}$

Surgery and rehabilitation: a roadmap to functional recovery $1=C$, $2=\mathrm{C}, 3=\mathrm{B}$

When our patients hurt: examining the relationship between pain and behaviour $1=C, 2=C, 3=B$

The placebo response and pain: understanding mechanisms and their importance in pain medicine $1=A, 2=B, 3=C$ 
Pain and the canine athlete: pain threshold, pain tolerance and drugs in competition $1=\mathrm{C}, 2=\mathrm{A}, 3=\mathrm{C}$

\section{Friday 3 April}

\section{NEUROLOGY}

Clinical reasoning in neurology: the 'five finger rule' $1=B, 2=B, 3=C$ Neuromislocalization: when our examination confounds us $1=C, 2=A$, $3=\mathrm{D}$

Odd episodes: when is a seizure not a seizure? $1=C, 2=D, 3=A$ Emergency seizure management: dos and don'ts 1=A, 2=B, $3=B$ Spinal emergencies: when to refer and when not to $1=A, 2=B, 3=B$ Caring for non-ambulatory patients: ethical considerations and more $1=B, 2=B, 3=A$

Geriatric neurology: diseases in an ageing population $1=\mathrm{D}, 2=\mathrm{B}, 3=\mathrm{A}$

\section{CONTINUOUS QUALITY IMPROVEMENT:}

\section{RCVS KNOWLEDGE}

RCVS Knowledge Canine Cruciate Registry 1=D, 2=D, 3=D

Helping the whole clinical team make a real difference to antibiotic use $1=\mathrm{D}, 2=\mathrm{D}, 3=\mathrm{D}$

Anaesthesia: what to do when things go wrong $1=C, 2=D, 3=B$

Management of feline chronic kidney disease $1=A, 2=B, 3=B$

Continuous quality improvement in practice: lessons from the RCVS Knowledge award winners $1=D, 2=D, 3=C$

\section{Saturday 4 April}

\section{CRITICAL CARE}

Sedation versus anaesthesia in sick patients $1=D, 2=C, 3=A$ SIRS, shock and sepsis $1=C, 2=B, 3=B$

DIC: causes, presentation and management $1=B, 2=A, 3=A$

Approach to the dyspnoeic cat $1=B, 2=A, 3=B$

\section{TRAUMA MEDICINE}

Triage of polytrauma 1=D, 2=C, 3=A

Head trauma $1=C, 2=D, 3=A$

Uroabdomen: presentation, diagnosis and management $1=A, 2=B$, $3=\mathrm{C}$

Assessing dirty wounds $1=\mathrm{D}, 2=\mathrm{B}, 3=\mathrm{D}$

\section{ANAESTHESIA}

Monitoring the monitors for anaesthesia 1=A, 2=C, 3=D

ECG monitoring under anaesthesia $1=D, 2=B, 3=A$

Blood pressure monitoring in anaesthetised animal: should I be worried? $1=C, 2=A, 3=D$

Capnography: what is it telling me? $1=D, 2=A, 3=C$

Pulse oximetry: when to be worried under anaesthesia $1=C, 2=B, 3=D$ CPCR for the anaesthetised patient $1=C, 2=C, 3=B$

\section{YEARS IN BIRMINGHAM}

\section{FIP $1=A, 2=B, 3=A$}

FIV $1=C, 2=D, 3=A$

Inappropriate urination/defecation in the cat $1=D, 2=C, 3=B$

Compulsive behaviour in the $\operatorname{dog} 1=A, 2=B, 3=C$

Oncology: the past, the present, the future $1=A, 2=D, 3=A$

Analgesia: the past, the present, the future $1=A, 2=D, 3=B$

Antibiotic use: the past, the present, the future $1=A, 2=B, 3=D$

Neurology: the past, the present, the future $1=C, 2=B, 3=D$

\section{STUDENT}

Where do you start with utilizing your team $1=C, 2=B, 3=A$

Where do you start with ultrasound? $1=D, 2=B, 3=B$

PTS: the elephant in the room - where do you start with discussing euthanasia? $1=\mathrm{D}, 2=\mathrm{B}, 3=\mathrm{A}$

Where do you start with preventative health care $1=B, 2=C, 3=D$

\section{Sunday 5 April}

\section{CLINICAL PATHOLOGY}

Laboratory testing for poisoning in practice: how, when and why we test for toxins $1=D, 2=B, 3=A$

Diagnosing poisoning in practice: interactive case discussion $1=C$ $2=B, 3=D$

How lab work helps me unravel the cause of a body cavity effusion $1=\mathrm{C}, 2=\mathrm{D}, 3=\mathrm{B}$

Nuts and bolts of culture and sensitivity testing $1=A, 2=C, 3=B$

Which antibiotic should I test for and which should I use $1=B, 2=A, 3=C$ Beyond microscopy: using molecular testing on routine cytology samples $1=C, 2=B, 3=C$

Diagnosis and classification of canine lymphoma from FNA samples with a combination of cytology and flow cytometry $1=C, 2=C, 3=B$

\section{DENTISTRY}

Initial approach to a dental case 1=C, 2=D, 3=A

Dental radiography: why and how $1=\mathrm{D}, 2=\mathrm{C}, 3=\mathrm{D}$

Common pitfalls in dentistry $1=B, 2=C, 3=D$

What makes extractions easier? $1=C, 2=A, 3=B$

Lingually displaced mandibular canines in pups and adults: a new epidemic? $1=\mathrm{D}, 2=\mathrm{D}, 3=\mathrm{B}$

Local anaesthetictechniques for dental cases 1=A, 2=B, 3=A

Holistic approach to analgesia of dental cases including aftercare $1=A$ $2=B, 3=D$

Dental trauma $1=C, 2=C, 3=D$

\section{BEYOND THE CLINICS}

Mind full or mindful: mental health awareness for the team 1=D, 2=B, 3=D

Resilience training: how to thrive! $1=\mathrm{B}, 2=\mathrm{B}, 3=\mathrm{A}$

Mentoring in practice $1=\mathrm{B}, 2=\mathrm{B}, 3=\mathrm{B}$

Managing perfectionism - good or bad? $1=A, 2=B, 3=B$

\section{Thursday 2 April}

\section{WETLAB}

Derm 101: cytology in practice $1=C, 2=B, 3=D$

Don't wing it: update your surgical and anaesthetic considerations in chickens $1=\mathrm{D}, 2=\mathrm{B}, 3=\mathrm{C}$

\section{SMALL GROUP SESSION}

Approach to oncological imaging $1=C, 2=A, 3=D$

Advanced ECG Interpretation 1=C, 2=A, 3=D

Diagnosis, management and treatment of portosystemic shunts: a team approach $1=\mathrm{C}, 2=\mathrm{B}, 3=\mathrm{B}$

\section{Friday 3 April}

\section{SMALL GROUP SESSION}

The highs and lows of medical cannabis $1=D, 2=A, 3=D$

Dentistry: complication of extraction 1=B, 2=D, 3=A

An advanced session on arrhythmias: integrating holter and ECG results to improve treatment with mechanistic understanding $1=\mathrm{A}$ $2=\mathrm{C}, 3=\mathrm{C}$

\section{WETLAB}

Surgery of the small intestine $1=B, 2=D, 3=A$

Rabbit anatomy refresher $1=A, 2=C, 3=D$

\section{Saturday 4 April}

\section{SMALL GROUP SESSION}

Reconstructive surgery $1=D, 2=C, 3=C$

Thyroid disease in dogs and cats $1=A, 2=C, 3=C$

Lung patterns $1=\mathrm{D}, 2=\mathrm{C}, 3=\mathrm{B}$ 